\title{
Study Site Personnel Primary Indicator
}

National Cancer Institute

\section{Source}

National Cancer Institute. Study Site Personnel Primary Indicator. NCI Thesaurus. Code C94148.

Specifies whether this is the main or principal study site personnel. 